\title{
The National Contexts of Post-national Citizenship
}

\author{
MITJA HAFNER-FINK, BRINA MALNAR and SAMO UHAN* \\ University of Ljubljana
}

\begin{abstract}
The article contributes to the literature on the changing concept of citizenship in the process of globalisation. It sets out from the thesis that the classic concepts of citizenship, which are linked to the nation state, are slowly but steadily losing their monopoly on explaining the relationship between individuals, the political community and government. Based on a theoretical discussion of the new models of citizenship, the authors seek to identify the elements of 'post-national' citizenship. The main research goal of the analysis is to discover the conditions in which elements of post-national citizenship are most likely to occur. The analysis is based on aggregated individual (survey) data (from the ESS 2008 and the EVS 2008) and macro contextual data on European Union countries. On the macro (country) level, the authors conduct a hierarchical cluster analysis and crisp set QCA and make the following findings. First, two groups of countries are formed: (a) a fairly homogeneous group of six 'post-national' citizenship countries; and (b) a more heterogeneous group of classic citizenship countries. Second, 'post-national' citizenship is to be expected in countries in which the following conditions are combined: on the one hand, secularised and post-industrial societies with less emphasis on a knowledge society, and on the other hand, societies with a stable national status where knowledge is important.
\end{abstract}

Keywords: post-national citizenship, typology of countries, globalisation, qualitative comparative analysis (QCA), European Union

Sociologický časopis/Czech Sociological Review, 2013, Vol. 49, No. 6: 867-901

\section{Introduction}

In the context of the ongoing processes of globalisation, nation states are slowly losing their monopoly on the concept of citizenship and especially citizenship rights. Citizenship status, rights and duties are no longer defined solely by membership in a nation state, that is, by national citizenship. This has necessitated a revision of the classic concept of national citizenship along the lines of a kind of a 'post-national' citizenship, which we understand as a synthesis based on (a) new phenomena emerging from globalising processes and (b) the way in which both the classic concepts of citizenship (republican and liberal) have attempted to ac-

\footnotetext{
* Direct all correspondence to: Mitja Hafner-Fink, University of Ljubljana, Faculty of Social Sciences, Kardeljeva pl. 5, SI-1000, Ljubljana, Slovenia, e-mail: mitja.hafner-fink@fdv. uni-lj.si.
} 
commodate these processes. The need for this revision is evident from a number of theoretical discussions and empirical studies. On the one hand, the (theoretical) discussions mostly focus on the macro level of countries or on the global perspective; on the other hand, empirical studies mostly deal with the various dimensions of citizenship at the micro level (individual level). Empirical studies that combine both micro and macro levels are rare. It is precisely this gap that our article aims to fill. In our empirical analysis we will examine how to combine data from two levels: individual (survey) data and macro (statistical) data about countries. The analysis will be conducted on the macro level (country level), where we combine aggregated survey data and contextual (statistical) data on countries.

We will start by considering the theoretical perspectives on citizenship, 'framed' by the two classic concepts of citizenship-the republican and the liberal. More precisely, we will start with those debates that seek to get a handle on the changes of citizenship in the process of globalisation. In an attempt to summarise these discussions we could say: the classic concepts of citizenship, which are linked to the nation state, are slowly but steadily losing their monopoly on explanations for the relationship between individuals, the political community and government. These discussions deal with every aspect of the changes that are occurring that is relevant to the concept of citizenship: the rights and duties of citizens, identity (affiliation), institutions and civil society, and the social and political participation of citizens. Through an empirical analysis we will demonstrate that the various (new) concepts of citizenship that go beyond the two classic concepts are meaningful and valid. These new concepts appear in the recent literature under various labels: post-modern, post-national, supranational, multilevel, flexible, transnational, global citizenship [e.g. Soysal 1996; Cohen 1999; Painter 2002; Frey 2003; Shore 2004; Castles 2005; Furia 2005; cf. Beck 2002; Held 2004; Faist 2009]. In our text, we will use the term 'post-national' citizenship.

The discussion of these concepts has mostly been limited to the macrosocietal level, while our first research goal is to develop and operationalise an empirical model of new citizenship at the level of individual citizens within the framework of EU countries. Thus, we are not dealing with institutional (or systemic) aspects of citizenship; rather, we are focusing on individual citizens. To pursue our goal, we use data from the European Social Survey (ESS) and the European Values Study (EVS). We will assume that the prevalence of a particular characteristic among citizens can be taken as an indicator of the presence of the new citizenship in a particular country. Individual-level data will be aggregated at the country level and a typology of countries will be prepared on the basis of aggregated individual data. This typology will be based on the following characteristics of individual citizens: the values of universalism, individualism, supra-national identity, attitudes to transnational institutions, political participation, and protest potential. Individuals possessing these characteristics could be provisionally labelled 'post-national citizens'. For this task we will use a hierarchical cluster analysis. 
Consistent with the starting point from which we set out to examine the relationship between globalisation and the emergence of new citizenship, we assume that the presence of post-national citizens is also influenced by the processes of globalisation at the macro-societal level; in the framework of a crossnational comparative approach, this can be observed in the characteristics of the countries investigated. Therefore, our second research goal is to identify combinations of conditions at the country level in which the presence of 'post-national' citizens occurs. We will focus on those conditions (country characteristics) that are associated with various aspects of the process of globalisation, in particular the (post-)modernisation process. In this respect, we explore combinations of conditions, such as social structure and the process of nation formation. We will pursue this second research goal by combining individual data (survey data from the ESS and the EVS) with macro-societal data and by applying a hierarchical cluster analysis and a crisp set qualitative comparative analysis (csQCA).

\section{Citizenship - the theoretical transition from classic to 'post-national' concepts}

The classic concept of national citizenship is in fact grounded in the concept of the republic, wherein citizenship is limited by the boundaries of the nation state, which grants citizenship status and associated rights and duties. Belonging to a community and the (political) action of citizens on behalf of a community are key dimensions of the republican concept of citizenship. At the heart of this concept of citizenship lies the notion of political participation, which is linked to certain prerequisites or competencies that assure the equality of the chosen, while excluding an important part of the population who are not citizens. In this sense, national citizenship is constructed around institutionalised racism because it excludes outsiders from access to entitlements typically on the basis of a racial or national identity [Turner 2000].

Among the classic approaches to citizenship the liberal concept appeared much later. The relationship between the individual and the state is defined in the liberal concept by a set of civil rights; the state must respect these rights and at the same time must not interfere in the life of the individual. Regardless of the differences between the two concepts, the background assumption of the classic (modern) paradigm of citizenship is that citizenship involves membership in a sovereign, territorial nation state. The nation state is not only a territorial organisation, monopolising legitimate rule within a bounded space, it is also a membership organisation [Cohen 1999: 252]. Citizenship in such a state is an instrument of social closure. It always has an ascriptive dimension and it always establishes privilege insofar as it endows members with particular rights denied to non-members [ibid.].

Over the past decade, variants of the so-called liberal cosmopolitan citizenship model, which highlights the individual's universal legal status, have ap- 
peared as a response to the deficiencies of the classic (national) concepts, both republican and liberal. We consider the liberal cosmopolitan model an attempt to reflect current trends in the changing traditional concepts of citizenship in the context of post-modernisation. In this sense, liberal cosmopolitan citizenship may be: (1) just a transitional phase towards post-national citizenship, or (2) the initial form (or at least a dimension) of this new post-national citizenship. According to this concept, a citizen is not a political actor but a legal person [Cohen 1999: 249] who abides by the laws and can expect legal protection from the state. At the core of this legal reconceptualisation of citizenship is the individual's universal legal status and individual rights. The universality of citizens' rights is not bound to a specific collective identity, membership, demos or territory; it is 'compatible' with the different statuses and identities of an individual. This means greater individualisation and, as various research has shown [e.g. Putnam 1995; Dalton 1996, 2008], the decline of some forms of political participation. Individuals with 'multiple' identities develop weaker group identity, or, as Turner puts it, 'cool loyalty' and 'thin solidarity' [Turner 2000: 28] to the nation, to a local community, or to a class. Political participation thus becomes more individualised, unbound to a specific territory, political community or social group. To understand this shift it is important to observe the transformation of forms of citizenship within the context of globalisation and the formation of transnational communities (e.g. the EU) that represent a transfer of sovereignty from the level of nation states to the level of supranational institutions. One consequence of this process is the 'disaggregation' or 'uncoupling' of various types of citizenship rights: an individual without formal nation state citizenship can have certain social rights that are (or are not) ensured at the level of a supranational political community [see, e.g., Benhabib 2005a, 2005b]. Citizenship is thus becoming cosmopolitan in various ways, such as: the internationalisation of human rights, the large volume of migration, and the formation of transnational political communities (e.g. the European Union). Despite some optimistic forecasts at the beginning of these processes, these changes are also ushering in new forms of inequality, exclusion and injustice, which are related to the fact that more and more complex citizenship relations are emerging [see, e.g., Faist 2009]. On top of the simple dichotomous division between citizens and non-citizens, new citizen statuses are developing. Kate Nash [2009], for example, lists the following: super-citizens, marginal citizens, quasi-citizens, sub-citizens, un-citizens.

In response to several (global) social currents that have challenged (and undermined) the nation state as the basis of the modern concept of citizenship, several authors have discussed the possibilities of developing a new concept of citizenship [e.g. Falk 1994; Soysal 1994, 1996; Cohen 1999; Delanty 2000; Turner 2000, 2001; Shore 2004; Benhabib 2007]. The process of globalisation, in general and with its various specific forms, has been one of the main reference points in these discussions. The following aspects of the globalisation process are also of special importance for our discussion: (a) the emergence of various transnational and supranational bodies (including the European Union); (b) the expanding power of 
global capitalism ('empire'); (c) massive international migration; (d) the intense development of modern communications and information technology; (e) global environmental problems and climate change and the problems of developing a (global) strategy to fight these problems. In such a globalising world, the nation state is not the exclusive source of individual (citizen) rights: the nation state framework as a space for practising citizenship from the 'top' (national government) and from the 'bottom' (individual citizens) has become too constraining. The exclusive territoriality and sovereignty inherent in the nation state model of citizenship are being transformed by the emergence of transnational economic practices, supranational legal regimes and post-national political bodies [cf. Cohen 1999].

The consideration of individuals (citizens) is particularly relevant in light of the processes of globalisation. Apart from citizens' rights and duties, here we have in mind two aspects of citizenship: membership in a community and participation in a community framework. By membership, we mean the following: the individual loses a solid reference point, there is a complexity and multiplicity of identities; the collective identities of individuals are becoming weaker, which ostensibly leads to the atomisation of citizens. It is not only about the deconstruction of national identity, but about the general decline in loyalty to any particular community [cf. Turner 2000]. With the disappearance of traditional loyalties, there are also changes in the field of social and political participation. On the one hand, we see a decline in 'organised' (institutionalised) social and political participation, while on the other hand studies point to the emergence of new forms of civic action and an increase in the volume of non-conventional and individualised forms of participation [e.g. Dalton 2008; Barnes 2006; Dalton 1996; Putnam 1995].

In this respect, we share the view of Joe Painter [2002], who regards the concept of citizenship in a 'global era' as a kind of synthesis of traditional conceptions of citizenship, where the main characteristic of this synthesis should be the idea of a multi-level citizenship: multi-level political communities (civil societies); the co-existence of different levels of democratic governance (from local to global); multiple (situational) identities; and post-modern (post-materialistic) values (environmentalism, tolerance and heterogeneity). Synthesis can also be seen as the overcoming of contradictions or the combining of the republican and liberal concepts of citizenship: communitarianism and individualism [cf. Bang and Soerensen 2001; van Houdt, Suvarierol and Schinkel 2011]. Citizenship models emerging within these processes could be generally described by the term 'post-national citizenship'.

\section{The analytical model of post-national citizenship}

We are not searching for a new model of (post-national) citizenship in general, but on the basis of the theoretical discussions of changing citizenship we aim to identify 'elements' of post-national citizenship on the basis of characteristics of individuals. In this respect, shifting the emphasis from a territorial (ethnic, national, 
state) principle to a temporal or issue-oriented principle [see Turner 2000] seems to be an obvious step in order to establish a post-national concept of citizenship in general. In fact, in a globalising world, the borders of political communities as spaces for practising citizenship at the individual level have become vague and fluid. Despite these processes, the nation state nevertheless remains sovereign in many respects: it still plays an important role in assuring the legal, social and economic security of citizens, and it remains an indisputable authority in ensuring its territorial integrity. Thus, our analyses will be conducted on a comparative cross-national level: we will seek to identify the societal conditions (within the framework of the nation state) in which post-national citizenship can emerge. In such a framework our approach is more exploratory than explanatory.

Our analysis is limited to EU member states. We based our selection of cases for analysis on the fact that the EU declares itself to be a (more or less) successful model of so-called supranational citizenship. According to its official narrative, the EU seeks to develop a stronger sense of European identity and citizenship above the level of the nation state, while simultaneously contributing to the blossoming of local, regional and national cultures and identities within it [see Shore 2004].

\section{Post-national citizens}

In order to identify the elements of post-national citizenship, we need to consider the transformation of the classic concepts of citizenship, both the republican and the liberal models. In this context, two dimensions of citizenship in particular are important: (a) 'active citizenship', which relates to the need for the active (political) participation of citizens-including protest activities (and protest potential in general); and (b) 'post-national identity', by which we mean identities beyond national identity, such as global, supranational, and transnational identities. We can find arguments in the literature for the existence of a global political community, a global civil society, and a global citizenship [see Kaldor 2003]. The concept of global citizenship also entails the notion of an 'active' global citizen who develops a kind of 'supranational identity' within the context of a global civil society. This characteristic could be defined as 'political cosmopolitanism', which expresses a positive attitude towards the United Nations or other supranational institutions [see Furia 2005: 343]. However, in order to realise the concept of a global (political) community, certain institutional conditions, such as 'international' NGOs, the institutions of global governance, and generally accepted norms and principles regarding human rights, are not in themselves sufficient. Real and 'globally operating' individuals (citizens) and a global public are required.

We expect 'globally operating' citizens to express a strong 'universalistic' value orientation, which, according to Schwartz, includes the following virtues: understanding, appreciation, tolerance, and the protection of the welfare of all people and of nature [see Schwartz 2007]. Individuals operating in such a (global) civil society are supposed to be more aware of social and political problems [cf. 
Kaldor 2003: 10] or to be more aware of the need to manage global problems such as environmental issues [cf. Falk 1994: 135]. The communities that support this concept of active citizens are 'global, virtual and thin, rather than local and thick' [Turner 2001: 203-204].

From the individual citizen's point of view, the coupling of the concepts of global civil society and citizenship also enhance the importance of 'individualism', which is replacing the identity attached to a certain (national) territory or to a certain (e.g. social, political) group. The diversity of (unstable) citizens' statuses and the growing global threats support the thesis that 'individualism and disloyalties could be functional in the global world of risk societies' [Turner 2000: 29]. Although in such conditions individualism can take the form of passivity, cynicism, or destructive criticism of the system, it is more relevant here to take individualism to mean civic actions which are tied not to a given community, but to the everyday priorities of an individual (citizen) [cf. Bang and Soerensen 2001]. In this sense, all aspects of citizens' political participation are relevant to our model-from conventional to unconventional forms of participation.

On the basis of the processes presented, and the theoretical views and the limitations set by the available data from the ESS and the EVS, we will focus on the following four aspects or elements (characteristics, dimensions) of post-national citizens:

- individuals as 'active citizens' (political participation, protest);

- 'post-national identity', expressed support for a supra-national authority and through a supra-national identity;

- 'universalism', openness and tolerance as value orientations;

- 'individualism', which is reflected both in terms of self-direction [cf. Schwartz 2007], and in terms of no pre-attachment to a collective identity; this means that any collective identity, including post-national identity, is situational and a matter of individual choice.

\section{The societal context of post-national citizenship}

We are not claiming that the presence of these elements (characteristics of citizens) also means that post-national citizenship in all its dimensions (from the characteristics of citizens, to the institutional setting at the system level) is already fully present in society. We assume, however, that a 'critical mass' of citizens who possess these characteristics is associated with the existence of a systemic (institutional) dimension of the new (post-national) citizenship. This association may be (causally) 'reciprocal'; however, we can say with confidence that both the existence of post-national citizens and the existence of 'post-national' institutions very likely result from the same macro-societal conditions. Within this framework we will try-from a comparative perspective-to ascertain whether we can speak of regularities in the distribution and prevalence of these individual elements (characteristics) across European countries. Our main research goal is to identify 
combinations of conditions within which the elements of post-national citizenship are substantially present. Generally speaking, in the context of European societies, we would expect to see more elements of post-national citizenship in those countries which have followed the post-modern (post-industrial) pattern of development [cf. Inglehart and Welzel 2005; Bang 2004; Beck 2002; Beck and BeckGrensheim 2002]. However, our narrow focus concerns the conditions that relate to the current macro-social situation of the countries compared; we will leave aside characteristics deriving from the historical backgrounds of these countries.

Based on various theoretical approaches to and empirical analyses of (post-)modernisation, globalisation, democratisation, citizenship and political culture, we consider the possible conditions in the following groups of macrosocial factors:

- The post-industrial structure of society, which is described as middle-class society with a large service sector and a moderate level of income inequalities [e.g. Inglehart and Welzel 2005; Achterberg 2006]. In empirical research and the discussions of various authors [e.g. Lipset 1959; Inglehart 1990; Inglehart and Welzel 2005; Achterberg 2006] the middle class is presented as an important factor in democratisation and (post-)modernisation processes. On the basis of this research, we can conclude that the values that support (post-)modernisation processes (such as self-expression, individualism, openness and tolerance) and that are also related to post-national citizenship are a middle-class phenomenon [cf. Inglehart and Welzel 2005: 56-61].

- Secularity, which we primarily relate to the concept of the decomposition of authority in (post-)modernisation processes, wherein the following aspects are of special importance to our model: the erosion of the power of the old hierarchical churches, the secularisation of authority, and emancipation from authority in general [e.g. Inglehart and Welzel 2005: 22, 25, 26].

- A knowledge-based society, which in our model is relevant as it is associated with the concept of the competencies of an active citizen [e.g. Beck and BeckGernsheim 2002: 32; Inglehart and Welzel 2005: 37-38, 45]. The aforementioned shift from a territorial (ethnic, national, state) principle to a temporal or issue-oriented principle [Turner 2000] is also related to so-called third-wave technology (communication, computerisation, internet), which, according to Beck, 'undermines historic territoriality' [Beck 2002: 32].

- Stable national status, which is important, considering our description of the evolution from classic (national) citizenship to post-national citizenship, because the formation of a new nation state tends to generate 'institutionalised racism' and exclusion [see Soysal 2002; Benhabib 2002]. Strong nationalism is to be expected in (a) a newly established nation state based mostly on ethnic identity, and (b) a situation where a nation state breaks up under pressure from internal nationalist movements [see Beck 2002: 38]. Beck labels this situation the 'ethnic globalisation paradox' [Beck 2002: 38]. Under these conditions the development of post-national citizenship is not likely to be observed. 
Since the concept of citizenship in general, and in particular the concept of post-national citizenship defined here, is related to the level of democracy (e.g. citizens' rights, the active participation of citizens), one would expect the level of democracy to be listed among these macro-societal factors. However, by limiting our investigation to EU countries, we are observing only consolidated democracies, which also include the new democracies from the latest wave of democratisation [cf. Schneider 2009]. We also assume that the general level of socio-economic development is an important factor. However, limiting our analysis to EU countries does not justify the inclusion of this factor in the model. ${ }^{1}$ In any case, we do not consider the conditions listed to be exhaustive, although we argue that they are grounded in various theoretical ideas which underlie the concept of post-national citizenship. Thus, our aim is not to verify an existing and elaborated theory of post-national citizenship, but rather to take steps in the direction of formulating such a theory.

We expect that, among the selected set of countries (the EU member states), several different combinations of the above-listed conditions will produce the expected outcome- $\mathrm{a}$ 'critical mass' of post-national citizens. This means that: (a) not all the conditions need necessarily be present; (b) the presence of one condition may in different combinations with other conditions lead to a different outcome; which means that (c) the presence or absence of a certain condition need not necessarily lead to symmetric outcomes. In the absence of available theories that would otherwise provide us with hypothetical combinations of the conditions of post-national citizenship, our analysis is primarily exploratory and focused more on the search for such combinations.

\section{Elements of post-national citizenship: the operationalisation and classification of EU countries}

With this goal in mind, we conducted our analyses within the geographical framework defined by data collected in 2008 in the fourth round of the European Social Survey (ESS), which was carried out in 28 countries $^{2}$ in the period from autumn 2008 to spring 2009 [ESS 2008]. Additionally, data were also taken from the fourth round of the European Values Study (EVS), which was carried out in

\footnotetext{
1 Viewed from a global perspective, we are comparing developed countries as measured by the Human Development Index for 2008 (HDI 2008). All of the countries compared have reached at least a high level of human development (see Human Development Reports (HDR) [UNDP 2012].

${ }_{2}$ The following countries were included in the fourth round of the ESS: Belgium, Bulgaria, Croatia, Cyprus, the Czech Republic, Denmark, Estonia, Finland, France, Great Britain, Germany, Greece, Hungary, Israel, Latvia, the Netherlands, Norway, Poland, Portugal, Romania, the Russian Federation, Slovakia, Slovenia, Spain, Sweden, Switzerland, Turkey, and Ukraine.
} 
47 countries (regions) (including all 28 countries from the ESS) in the period from 2008 to 2010 [EVS-GESIS 2010]. Since we 'nested' our hypothetical model within the framework of the European Union, our analyses are limited to EU countries, which means that only 21 countries are included: Belgium, Bulgaria, Cyprus, the Czech Republic, Denmark, Estonia, Finland, France, Great Britain, Germany, Greece, Hungary, Latvia, the Netherlands, Poland, Portugal, Romania, Slovakia, Slovenia, Spain, and Sweden. Using aggregated individual data, we classified the countries on the basis of the above-mentioned elements of new citizenship and expected that this classification would reveal some explainable patterns of the emergence of elements of the new concept of citizenship. Later on, using qualitative comparative analysis (QCA) we will explore the possible combinations of conditions for the emergence of a significant presence ('critical mass') of these elements of post-national citizenship.

\section{Indicators of post-national citizenship}

Using ESS and EVS data we operationalised the above-mentioned four elements (dimensions) of the new (post-national) citizenship through the following six indicators: conventional political participation, protest potential, trust in international organisations, supra-national identity, universalistic values, and self-direction values (see Table 1).

Conventional (institutional) political participation is the first indicator of the extent to which 'individuals are active citizens'. Using data from the ESS, we prepared an aggregated measure of the proportion (\%) of respondents who were active (during the 12 months prior to the survey) in at least one of the following

Table 1. Elements and indicators of post-national citizenship

\begin{tabular}{|c|c|c|}
\hline Elements & Indicators & Data source \\
\hline \multirow[t]{2}{*}{ Individuals as active citizens } & $\begin{array}{l}\text { - Conventional (institutional) political } \\
\text { participation }\end{array}$ & ESS \\
\hline & - Protest potential & EVS \\
\hline \multirow[t]{2}{*}{ Post-national identity } & $\begin{array}{l}\text { - Supranational identity (Europe, the } \\
\text { world as a whole) }\end{array}$ & EVS \\
\hline & $\begin{array}{l}\text { - Trust in international organisations } \\
\text { (the EP, the UN) }\end{array}$ & ESS \\
\hline Universalism & $\begin{array}{l}\text { - Index of universalism from the ESS } \\
\text { human values scale }\end{array}$ & ESS \\
\hline Individualism & $\begin{array}{l}\text { - Self-direction index from the ESS hu- } \\
\text { man values scale }\end{array}$ & ESS \\
\hline
\end{tabular}


activities: contacting a politician; working in a political party; working in another organisation; wearing a campaign badge/sticker [ESS 2011].

Protest potential is the second indicator of the extent to which the surveyed 'individuals are active citizens'. Using data from the EVS, we first prepared a measure on the level of individuals-a composite index on a scale of 0 to 10 . The index includes actual participation ever in the past (a score of 2) or willingness to participate (a score of 1) in the following five forms of protest: signing a petition, joining a boycott, attending lawful demonstrations, joining an unofficial strike, and occupying buildings or factories [EVS 2010]. The mean value of this index at the country level was prepared as an aggregated measure of protest potential.

Supra-national identity is the first indicator of the degree of 'post-national identity'. This is measured as the sense of belonging to two supra-national geographical groups: Europe and the world as a whole. We used data from the EVS, where respondents were able to choose two possible entities to which they felt they belonged out of a total of six options referring to entities on different levels, from their immediate locality to the world as a whole [EVS 2010]. An aggregated measure of the proportion (\%) of respondents who felt that they belonged to Europe and/or the world was prepared at the country level.

Trust in international organisations is the second indicator for the dimension of 'post-national identity'. This is measured as the level of trust in international bodies: the United Nations and the European Union. We used two ESS items measuring respondents' trust in the European Parliament and in the United Nations on a scale from 0 (no trust at all) to 10 (complete trust) [ESS 2011]. The correlation (on pooled data) between these two items was quite high (Pearson's $r=0.731$ ) and we prepared the index support for global governance simply as a (rounded) mean value of both items (on a scale of 0 to 10). The mean value of this index at the country level was prepared as an aggregated measure of trust in international organisations.

Universalism is measured with Schwartz's value scale [see Schwartz 2007]. We used the universalism index from the ESS human values scale [see Schwartz 2007], which contains three items (responded to on a scale from 1 to 6): the equal treatment of every individual person; tolerance and understanding of people who are different; environmental care [ESS 2011]. To correct respondents' response tendencies we did not use absolute scale values, but rather applied centring to each person's responses (a mean value for each index) based on the person's overall mean value for all items [Schwartz 2007: 180]. In this way we formed an index representing the relative importance of universalism to each respondent-within the theoretical model of ten basic human values, which were measured on the ESS human values scale [Schwartz 2007: 180]. In the ESS data set as a whole individual scores for the centred scale fit within the range of -3.32 to 3.35, where a lower value indicates that values are of lower relative importance compared to other basic human values in the model. The mean value of 
this index at the country level was prepared as an aggregated measure of universalism.

Schwartz's self-direction values scale [see Schwartz 2007] is used to measure the extent of a citizen's individualism. We used the self-direction index from the ESS human values scale [see Schwartz 2007], which contains two items (responded to on a scale from 1 to 6): it is important to have new ideas and be creative; it is important to make one's own decisions and not depend on others [ESS 2011]. The above-mentioned procedure to correct respondents' response tendencies was also applied to this index. Individual scores for the corrected (centred) self-direction scale fit within the range of -4.24 to 3.43 , where a lower value indicates that less importance is placed on self-direction values. The mean value of this index at the country level was prepared as an aggregated measure of individualism (self-direction).

\section{Classification of countries}

On the basis of these six indicators we also prepared an index of post-national citizenship at the country level. Aggregated measures for all six indicators were first standardised within the observed minimum-maximum range on a scale of 0 to 10 . The results of the principal component analysis confirmed our expectations: only one component (explaining $61.6 \%$ of the total variance) out of all six indicators (loadings from 0.610 to 0.931 ) was formed. The index was then calculated as a mean value of these six standardised indicators. Thus, we can rank the $21 \mathrm{EU}$ countries ranging from the country with the lowest level of post-national citizenship to the country with the highest level of post-national citizenship.

A simple ranking of countries shows that nine countries are ranked from the average to the highest value of the post-national citizenship index: the United Kingdom (right on the average), Spain, Germany, Belgium, the Netherlands, France, Denmark, Sweden, and Finland with the highest value (see Figure 1). Relatively consistently high values for all six indicators can be observed among the top six countries (with the exception of a lower value for trust in international institutions in France), while the values for the United Kingdom, Spain and Germany are less consistent (for example, Germany has the highest value of self-direction and very low values for supranational identity and trust in international institutions) (see Figure 1).

To obtain a clearer division between 'post-national citizenship countries' and 'classic citizenship countries' we used a cluster analysis based on the six (above-presented) aggregated indicators of the new (post-national) concept of citizenship, namely: institutional political participation; protest participation; universalistic values; self-direction values; supra-national identity; and trust in international organisations. We used a hierarchical cluster analysis of all $21 \mathrm{EU}$ 
Figure 1.The classification (ranking) of EU countries on the basis of the post-national citizenship index

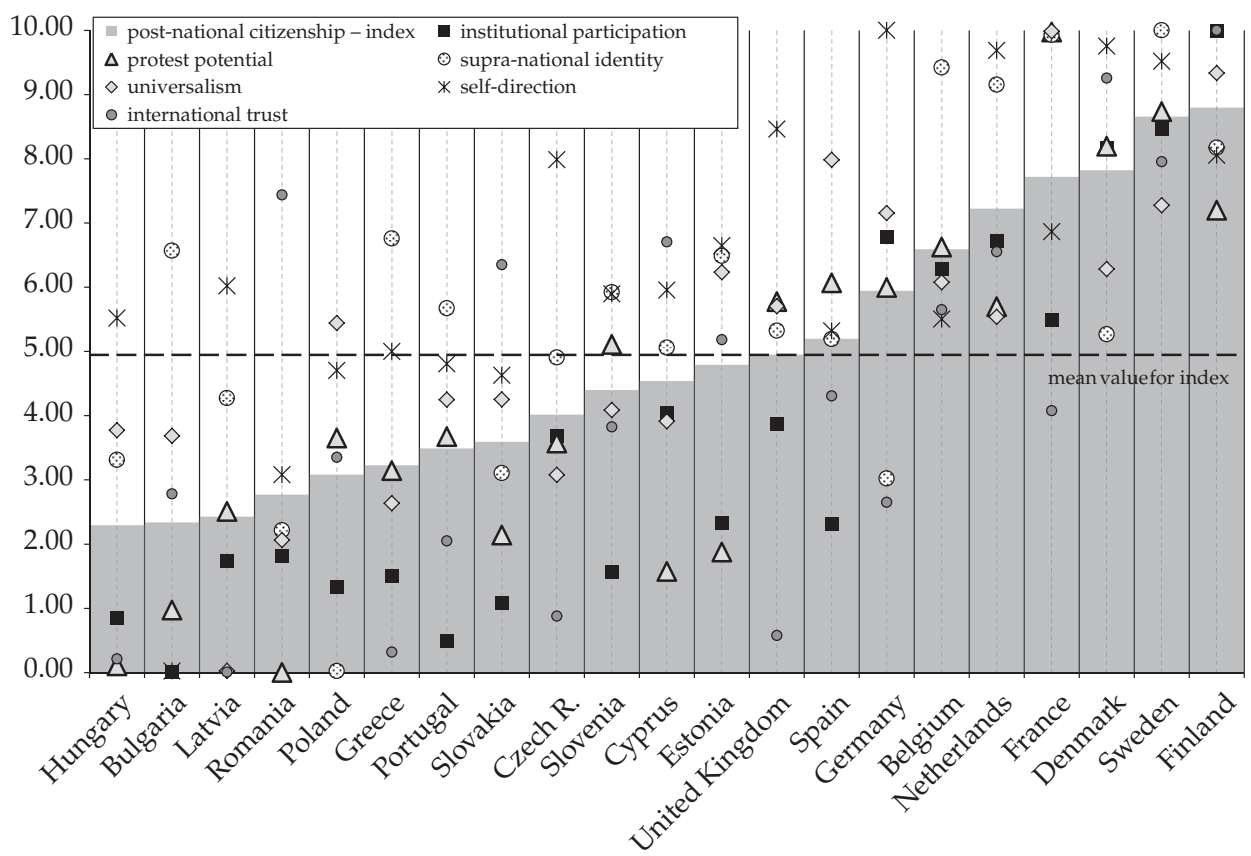

Source: ESS 2008, EVS 2008.

Note: The post-national citizenship index consists of six indicators: institutional political participation, protest potential, supra-national identity, trust in international institutions, universalism, and self-direction (standardised scale on min.-max. range from 0-10).

countries included in the fourth round of the ESS. Ward's method was used for the clustering, while the squared Euclidian distance for standardised data (scale $0-10$, based on the min.-max. range) was used to measure the (dis)similarities amongst the countries. Based on a graphic representation of the results (using a dendrogram), the countries can be meaningfully clustered into two main groups: (a) 'post-national citizenship countries' - the six countries with the highest values on the post-national citizenship index (three Nordic countries-Denmark, Finland, and Sweden; and three Western European countries-the Netherlands, Belgium, and France); and (b) a group of fifteen other countries (see Figure 2). Within the second group, a sub-group of three countries was formed: Germany, the United Kingdom and the Czech Republic. In these three countries we find the same pattern of the six indicators of post-national citizenship: an approximately average value on the post-national citizenship index, a low degree of trust in international institutions, and a high degree of self-direction (see Figure 1). Given 
Figure 2. Classification of European countries based on the four dimensions of postnational citizenship (Ward linkage)

Rescaled Distance Cluster Combine

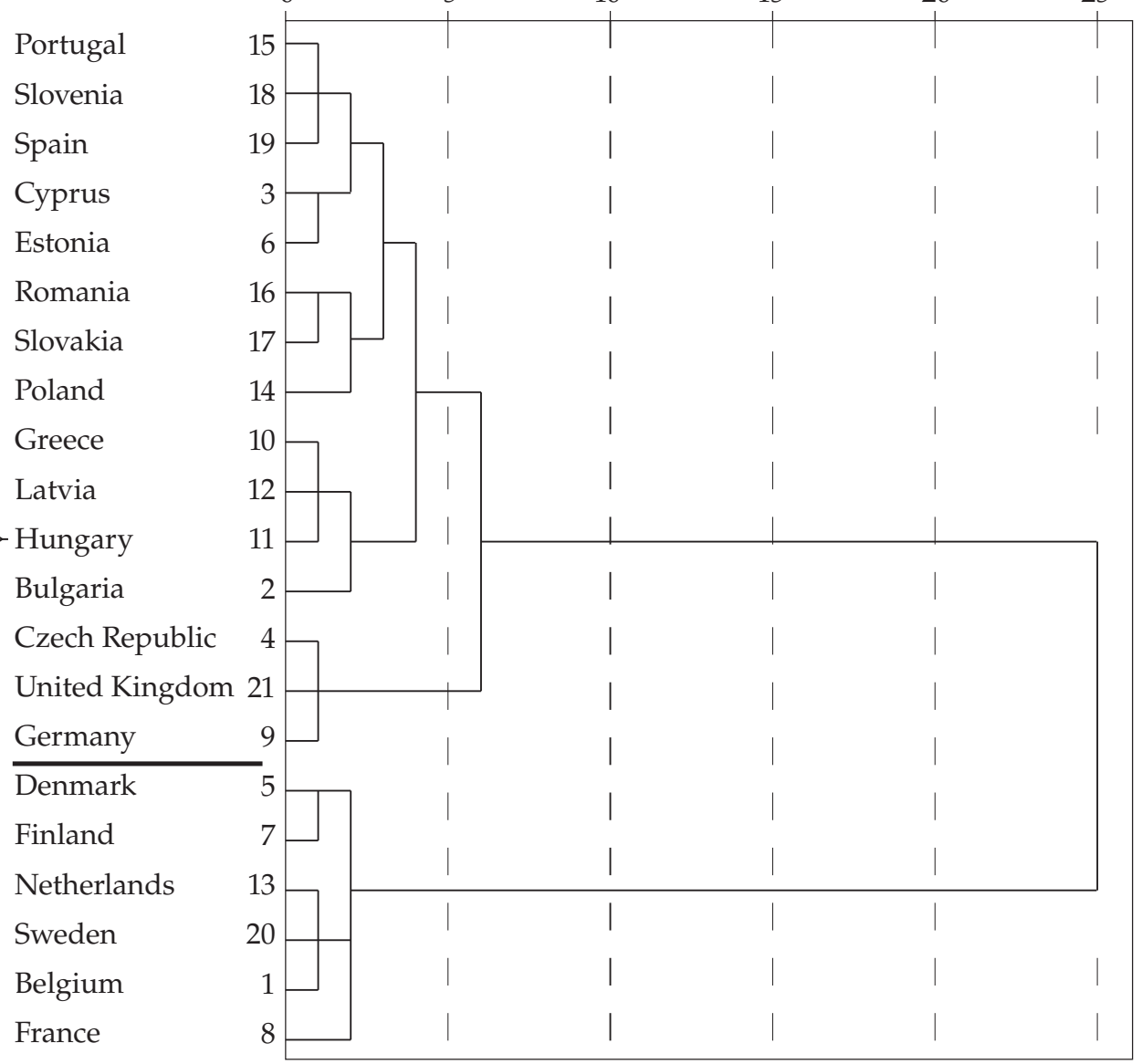

Source: ESS 2008, EVS 2008.

this pattern, we can speak of these three countries as occupying an intermediate position between the group of 'post-national citizenship countries' on one side and the 'classical citizenship countries' on the other side.

The classification of countries above presents just a relative ranking of countries. To make an assessment about the presence of post-national citizenship, we need information about the actual proportion of citizens with this attribute. In 
the case at hand, only two individual indicators (measuring two elements of post-national citizenship) can provide us with this kind of information: (a) active citizenship measured as the proportion of all citizens who are active in at least one (observed) form of institutionalised or individualised political participation (ESS 2008 data); and (b) a supra-national identity measured as the proportion of citizens who feel they belong to Europe and/or the world (EVS 2008 data). The data show that, even in the group of 'post-national citizenship countries', the proportion of citizens possessing these attributes barely reaches $50 \%$. Regarding active citizenship, only in Sweden does the proportion of citizens who are active in at least one individualised activity (boycotting, signing a petition, demonstrations) exceed 50\% (60.6\%). In 'classic citizenship countries', especially in the postcommunist countries of Eastern Europe, the percentages are substantially lower and only rarely exceed $20 \%$. The level of supra-national identity is lower and the differences between countries are smaller than in the case of measures of active citizenship. The highest percentage of respondents who feel a supra-national identity in the group of 'post-national citizenship countries' (and in general) is in Sweden at $30.8 \%$.

\section{The social context of the emergence of elements of post-national citizenship}

We shall now attempt to identify the macro-societal conditions that favour the spread of elements of post-national citizenship. Therefore, using a crisp set qualitative comparative analysis (csQCA) [see Rihoux and Ragin 2009; Rihoux and De Meur 2009] we shall explore the various possible combinations of these conditions. ${ }^{3}$

Why didn't we apply a multivariate (quantitative) analysis of causal relations, such as regression analysis, instead of csQCA? Our reason for opting not to perform a regression analysis was technical: namely, the small number of cases (21 countries). The fact that we are not interested in the influence of individual factors, but rather in the combination of conditions for post-national citizenship, led us to opt for the QCA. The QCA as a configurational comparative method was designed precisely for the analysis of complex causal configurations where researchers do not investigate independent influence of individual factors but rather the influence of combinations of factors or 'conjunctural causation' [see Ragin 1987, 2000; Berg-Schlosser et al. 2009; Schneider and Wagemann 2012]. Our decision for the crisp set QCA (and not for the fuzzy set QCA) was mostly based on our initial interest in drawing a clear division between 'post-national citizenship countries' and other ('classic citizenship') countries, which was implemented in the initial step with the application of cluster analysis.

${ }^{3}$ Using Tosmana software [Cronqvist 2007] and fsQCA 2.0 software [Ragin, Drass and Davey 2006]. 
The operationalisation of selected societal conditions and the preparation of data for analysis

The exploration of possible combinations of conditions leading to post-national citizenship is based on the analytical model developed above, in which the following four conditions were discussed: the structure of a post-industrial society; secularisation; a knowledge-based society; and the stability of national status. These conditions were operationalised as follows:

(a) The structure of a post-industrial society was identified using the following indicators: the proportion of the population who are middle class; ${ }^{4}$ the proportion of people employed in the service sector [Eurostat 2008]; the income gap-a quintile ratio [Eurostat 2008]. We used a hierarchical cluster analysis (Ward's method, the squared Euclidian distance for standardised data) to classify the countries. The following three groups of countries were formed: (1) 'post-industrial middleclass societies', which include Belgium, France, Germany, Denmark, Sweden, the Netherlands, the United Kingdom, and Cyprus (the distinctive characteristics of this cluster are: a large middle class, moderate inequalities, a large service sector); (2) 'high-inequality industrial societies', which include Greece, Spain, Portugal, Latvia, Bulgaria, Poland, Estonia, and Romania (the main distinctive characteristics of this cluster are: the highest levels of inequality and the smallest middle class); (3) 'low-inequality industrial societies', namely Finland, Slovakia, the Czech Republic, Slovenia, and Hungary (the main characteristics of this group being the lowest level of inequality and a small service sector (see Appendix 1). In the analysis, inclusion in the first cluster is understood as the presence of a postindustrial society structure (postind).

(b) The secularity of society was identified using the following indicators from the ESS 2008 survey data: the proportion of the population who do not attend religious service; the proportion who 'do not pray'; the self-perception of religiosity (aggregated mean value on a scale from 0 to 10; higher values indicating a higher degree of religiosity) [ESS 2008, 2011]. We again used the hierarchical cluster analysis to classify the countries, which revealed three distinctive clusters: (1) 'highly secularised countries'-France, Sweden, Belgium, the Netherlands, Denmark, the United Kingdom, Estonia, and the Czech Republic; (2) 'secularised countries'-Bulgaria, Hungary, Latvia, Slovenia, Slovakia, Portugal, Spain, Germany, and Finland; (3) 'less secularised countries' - Cyprus, Greece, Romania, and Poland (see Appendix 2). The results of the classification (the classification

\footnotetext{
${ }^{4}$ We measured the proportion of the population who are middle class using data from the ESS 2008 on the basis of the European Socio-economic Classification (ESeC) by merging the following categories: (2) lower grade professional, administrative and managerial occupations and higher grade technician and supervisory occupations; (3) intermediate occupations; (4) small employer and self-employed occupations (excluding agriculture); (6) lower supervisory and lower technician occupations (for more on the ESeC, see Rose and Harrison [2007]).
} 
tree, the distances between clusters, the structure of clusters) suggest that inclusion in both of the first two clusters might indicate the presence of the condition of 'secularity'. However, this decision would lead to a skewed distribution: in most cases (in seventeen of them) the condition would be present, while in only four cases it would be absent. Thus, we decided that only inclusion in the first cluster would be used as an indicator of the presence of the secularity condition (sclrz).

(c) Knowledge-based societies were identified using the following indicators: Internet use (\% of population) [UNDP 2012]; public expenditure on education (\% of GDP) [Eurostat 2008]; and life-long learning (\% of population included) [Eurostat 2008]. A hierarchical cluster analysis was applied, resulting in two distinct clusters of: (1) 'knowledge-based societies' — Finland, Denmark, Sweden, the Netherlands, and the United Kingdom, all of which exhibited high values on all three indicators; (2) other countries with low values on all three indicators (see Appendix 3). Inclusion in the first cluster is understood as the presence of a knowledge-based society ( $k n w$ gsoc).

(d) The 'stability' of national status (natsta), which we understand as the finalisation of the process of forming a nation state and the absence of any disintegrative ethnic (nationalistic) processes. We excluded from the group of countries with a stable national status those countries that (a) were recently formed (following the collapse of the communist bloc in Eastern Europe) within current national boundaries (reunified Germany, ${ }^{5}$ the Czech Republic, Slovakia, Slovenia, Estonia, and Latvia), (b) face the challenge of ethnic or nationalist separatist movements (Spain, United Kingdom), and (c) are 'divided' countries (Cyprus, Belgium). The following countries are in the group with a stable national status (i.e. that condition is present): Bulgaria, Denmark, Finland, France, Greece, Hungary, the Netherlands, Portugal, Romania, and Sweden.

Each country in the comparison was considered to be a combination of the conditions linked to a specific outcome-included or not included in the cluster of 'post-national citizenship countries' (postnatc). Each condition was monitored in combination with other conditions. Our analytical goal was to explore (discover) the combinations of conditions that led to the outcome of a 'post-national citizenship' society. All the variables representing the conditions and the outcome were dichotomised (present -1 ; absent -0 ) on the basis of the operationalisation described above.

The presence of the outcome (post-national citizenship) and three of the conditions (post-industrial structure, secularisation, and a knowledge society) were identified analytically using a hierarchical cluster analysis (as presented above). Both the outcome and the conditions are complex social phenomena that could only be observed through several dimensions and measured with different indi-

\footnotetext{
${ }^{5}$ Reunification has impacted the creation of some socio-political divisions and conflicts while it has also added to ethnic German self-confidence in relation to ethnic/immigrant minorities [cf. Berdahl 2005; Silver 2010].
} 
cators-subjective and objective. One other possible solution would be to develop composite indices of standardised indicators for each dimension. However, in the next step we would have had problems with the dichotomisation necessary for the csQCA. This would have been a somewhat arbitrary move since we were unable to find sound theoretical arguments for setting thresholds on standardised indices [cf. Schneider and Wagemann 2010: 403]. The same problem would arise if we tried to set qualitative anchors to define fuzzy sets. Therefore, we decided in favour of an alternative approach: based on the theoretical criteria we identified the relevant dimensions of each phenomenon [cf. Rihoux and De Meur 2009: 42; Yamasaki and Rihoux 2009: 130]. From these dimensions and a hierarchical cluster analysis we classified the countries and produced separate typologies of countries according to each of the above-mentioned phenomena. The presence/absence of a condition (or the outcome) was defined as the (non)inclusion of a corresponding cluster within each typology.

\section{The results of the analysis}

The analytical model presented above revealed nine configurations of conditions for the emergence of post-national citizenship in the 21 countries investigated: there are five combinations of conditions in the fifteen 'classic citizenship countries' (combinations 1-5), and four combinations of conditions in the six

Table 2. Truth table-the combinations of conditions (presence/absence) for 'post-national' citizenship in EU countries

\begin{tabular}{|c|c|c|c|c|c|c|}
\hline \multirow{2}{*}{$\begin{array}{l}\text { Comb. } \\
\text { no. }\end{array}$} & \multicolumn{4}{|c|}{ Conditions } & \multirow{2}{*}{$\begin{array}{l}\text { Outcome } \\
\text { postnatc }\end{array}$} & \multirow{2}{*}{ Countries } \\
\hline & natsta & knwgsoc & postind & sclrz & & \\
\hline 1 & 0 & 0 & 0 & 0 & 0 & $\begin{array}{l}\text { Latvia, Slovakia, } \\
\text { Slovenia, Spain }\end{array}$ \\
\hline 2 & 0 & 0 & 0 & 1 & 0 & Czech R., Estonia \\
\hline 3 & 0 & 0 & 1 & 0 & 0 & Cyprus, Germany \\
\hline 4 & 1 & 0 & 0 & 0 & 0 & $\begin{array}{l}\text { Bulgaria, Greece, } \\
\text { Hungary, Poland, } \\
\text { Portugal, Romania }\end{array}$ \\
\hline 5 & 0 & 1 & 1 & 1 & 0 & United Kingdom \\
\hline 6 & 0 & 0 & 1 & 1 & 1 & Belgium \\
\hline 7 & 1 & 1 & 0 & 0 & 1 & Finland \\
\hline 8 & 1 & 0 & 1 & 1 & 1 & France \\
\hline 9 & 1 & 1 & 1 & 1 & 1 & $\begin{array}{l}\text { Denmark, Netherlands, } \\
\text { Sweden }\end{array}$ \\
\hline
\end{tabular}


Figure 3. Venn diagram-visualisation of the data (combinations) in Table 2

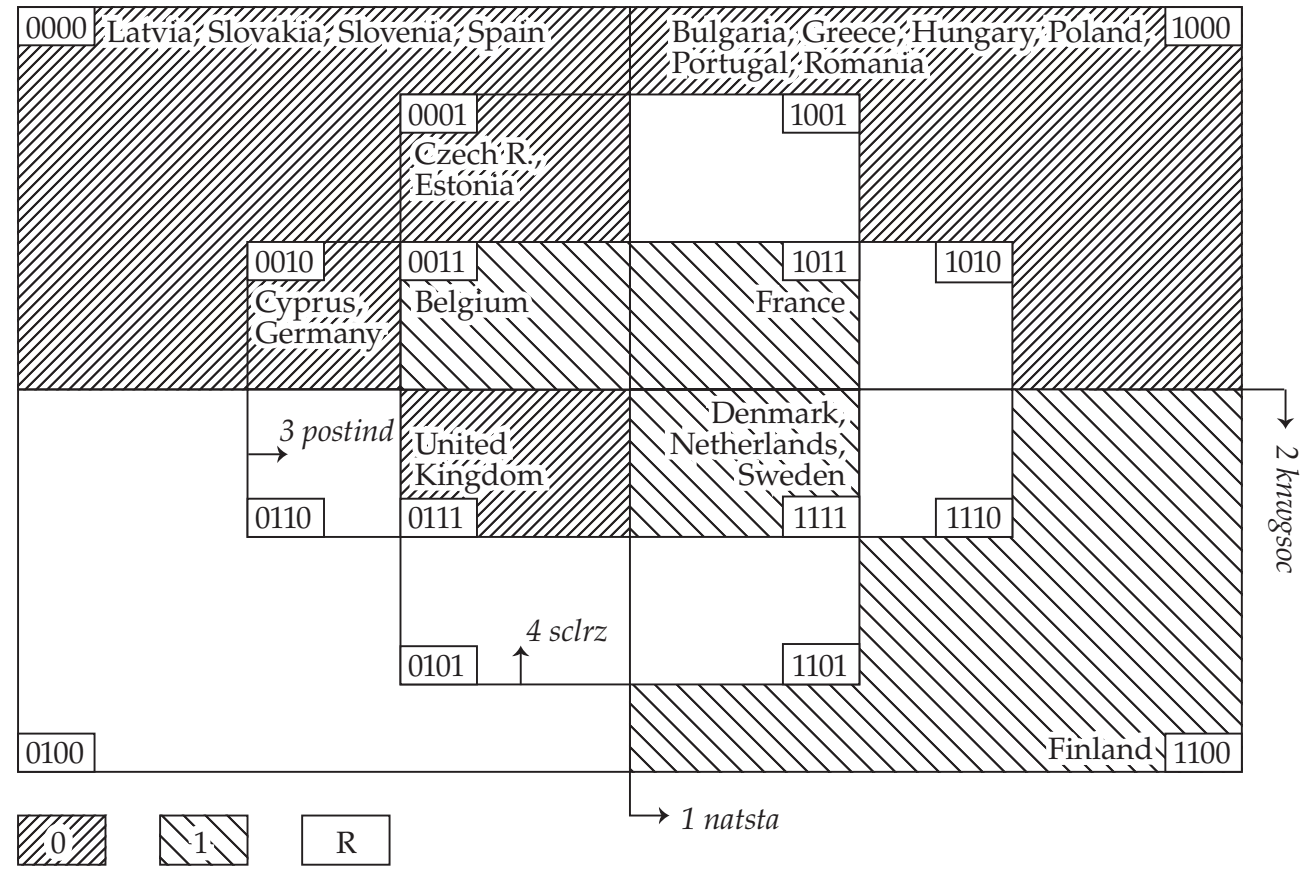

Note: $0=$ absence of the outcome, $1=$ presence of the outcome, $\mathrm{R}=$ logical remainder.

Created in Tosmana.

'post-national citizenship' countries (combinations 6-9) (Table 2). In three 'postnational citizenship' countries (Denmark, the Netherlands, and Sweden), all four conditions are present. In France only the importance of knowledge is absent. In Finland two conditions are missing (post-industrial structure and secularity); and in Belgium another two conditions are missing (stable national status and the importance of knowledge) (Table 2).

We ought to point out that the combinations in the truth table suggest independent or additive effects as opposed to the complex and conjunctural causation we had expected. In countries in which the outcome is not present, no more than one of the four single conditions is present, while post-national citizenship is found in countries where at least two conditions are present. The United Kingdom, which was not classified as a 'post-national citizenship' country, proved the exception-only one condition is absent (stable national status). If we compare the combination in the UK with the combination in Belgium (in which 'post-national citizenship' was present), this result does not support the thesis about additive effects. In Belgium only two conditions were present, namely post-industrial society and secularity; while in the UK there was one additional condition present: 
a 'knowledge-based society'. Thus, we have at least one case which proves the validity of our proposition about the combinatorial effects of factors. However, it is necessary to note the problem of limited empirical diversity: the fact that in the truth table there are seven unobserved combinations (out of the sixteen theoretically possible combinations) or 'logical remainders' (i.e. combinations of conditions that do not emerge in any of the cases observed $)^{6}$ [see Rihoux and De Meur 2009]. There are two possible reasons for this: (a) missing cases (data) —only 21 countries were included in the analysis, although we had initially planned to cover all $27 \mathrm{EU}$ countries; (b) combinations that are theoretically possible but are not covered in the truth tables do not empirically exist. In any case, the results of the analysis below should be viewed in the light of these limitations.

An analysis of the necessary conditions showed that there is no necessary condition for the presence of the outcome ('post-national citizenship'). However, the absence of a 'knowledge society' could be understood as a non-trivial, necessary (or at least 'quasi-necessary') condition for the absence of 'post-national citizenship' - in only one case, namely the UK, is this conclusion not supported. A more detailed analysis ${ }^{7}$ showed that the consistency of the absence of a 'knowledge society' as a necessary condition for the absence of 'post-national citizenship' attained a value of 0.933 (coverage $=0.875$ ). When we apply Schneider and Wagemann's formula for the relevance of necessity [see Schneider and Wagemann 2012: 236 $]^{8}$ we obtain a value of 0.833 , which also supports our claim about the non-trivialness of the absence of a 'knowledge society' as a necessary condition for the absence of 'post-national citizenship'.

To investigate the possible various (combinations of) conditions sufficient to lead to the outcome of 'post-national citizenship', we conducted the crisp setanalysis (csQCA) of the truth table. The analysis was done as a simplification (minimisation) of the configurations in the 'truth table' (see Table 2) by comparing two configurations with the same outcome (a 'post-national citizenship' country, or a 'not post-national citizenship' country): in pairs where configurations differ by only one condition (its presence or absence) this condition is eliminated as unimportant for the outcome. Using fsQCA 2.0 software, it is possible to produce three solutions: (a) in order to obtain a complex solution only empirically existing combinations are used (i.e. no logical remainders are used); (b) to obtain a parsimonious solution all logical remainders may be used; (c) to obtain an intermediate solution only (theoretically) meaningful logical remainders are taken into account [see Ragin 2009: 110-111]. In our analysis, for the intermediate solution, we assumed of each condition that its presence supported the positive outcome.

\footnotetext{
${ }^{6}$ Empty (white) fields in the Venn diagram represent logical remainders (see Figure 3).

7 The fsQCA 2.0 software was used.

8 The formula 'covers' both possible sources of trivialness: (a) the situation in which the condition is present in virtually all cases, and (b) the situation in which the condition and outcome are effectively constants [see Schneider and Wagemann 2012: 144-147, 233-235].
} 
Table 3. The consistency and coverage of solutions for the positive outcome

\begin{tabular}{|c|c|c|c|}
\hline & $\begin{array}{c}\text { Raw } \\
\text { coverage }\end{array}$ & $\begin{array}{l}\text { Unique } \\
\text { coverage }\end{array}$ & Consistency \\
\hline \multicolumn{4}{|l|}{ Complex solution: } \\
\hline knwgsoc * POSTIND * SCLRZ & 0.333 & 0.167 & 1.000 \\
\hline NATSTA * POSTIND * SCLRZ & 0.667 & 0.500 & 1.000 \\
\hline NATSTA * KNWGSOC * postind ${ }^{*}$ sclrz & 0.167 & 0.167 & 1.000 \\
\hline \multicolumn{4}{|l|}{ Solution consistency $=1.000$} \\
\hline \multicolumn{4}{|l|}{ Solution coverage $=1.000$} \\
\hline \multicolumn{4}{|l|}{ Intermediate (and parsimonious) solution: } \\
\hline KNWGSOC ${ }^{*}$ NATSTA & 0.667 & 0.667 & 1.000 \\
\hline SCLRZ * POSTIND * knwgsoc & 0.333 & 0.333 & 1.000 \\
\hline \multicolumn{4}{|l|}{ Solution consistency $=1.000$} \\
\hline Solution coverage $=1.000$ & & & \\
\hline
\end{tabular}

Note: Calculated in fsQCA 2.0.

For the complex solution, the four configurations of conditions for 'postnational citizenship countries' can be simplified into three configurations: the combination for Finland, with no simplification (all four original conditions are present), and two combinations each with three conditions. The complex solution (the combination of conditions for outcome 1) (Table 3) is formulated as follows (Formula 1): ${ }^{9}$

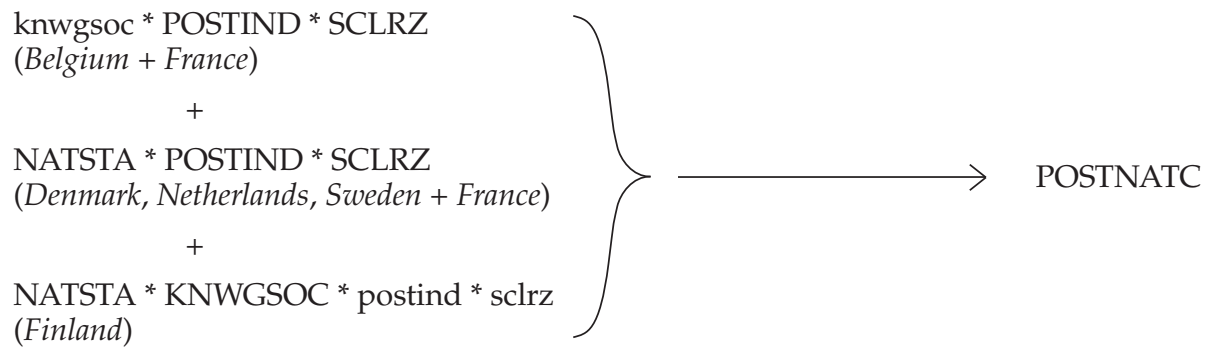

\footnotetext{
${ }_{9}$ Uppercase letters indicate the presence of a condition or outcome (value 1 in the truth table), lowercase letters indicate the absence of a condition or outcome (value 0 in the truth table), an asterisk ${ }^{*}$ ) is used to indicate the logical 'AND' (a combination of conditions), and a plus sign (+) is used to indicate the logical 'OR' (the co-existence of equivalent combinations of conditions with the same outcome).
} 
For the parsimonious solution, we repeated the analysis, but this time took into account the logical remainders (only two logical remainders were used). The parsimonious solution (see Table 3) is formulated as follows (Formula 2):

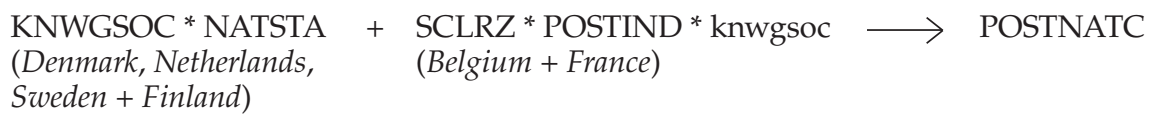

Finally, we conducted the csQCA to produce an intermediate solution (between a complex and a parsimonious one), and the result was identical to the parsimonious solution (see Formula 2 and Table 3).

Further analyses examining the negative outcome (the absence of 'post-national citizenship') support our thesis of a specific (intermediate) position, not only for the United Kingdom, but also for Germany and the Czech Republic (see the results of the cluster analyses in Figure 2): these three countries were covered with solution terms (combinations of conditions) referring to the lowest unique coverage. The intermediate solution provides us with the following four resulting combinations:

- natsta * postind:

- natsta* sclrz:

- natsta ${ }^{*}$ KNWGSOC:

- sclrz * postind * knwgsoc: uniquely covering the Czech Republic and Estonia (0.133), and additionally Latvia, Slovakia, Slovenia, and Spain;

uniquely covering Germany and Cyprus (0.133), and additionally Latvia, Slovakia, Slovenia, and Spain;

uniquely (exclusively) covering the United Kingdom (0.067);

uniquely covering Bulgaria, Greece, Hungary, Poland, Portugal, Romania (0.400), and additionally Latvia, Slovakia, Slovenia, and Spain.

\section{Discussion}

To sum up, based on both the parsimonious solution and the intermediate solution, which are both identical, we find that there are two combinations (paths) that are sufficient to lead to a 'positive' outcome-the presence of a critical mass of post-national citizens: (a) the presence of a 'stable nation status' and a 'knowledge society'; and (b) the presence of 'secularity' and a 'post-industrial social structure' when a 'knowledge society' is absent. The first sufficient combination is observed in the three Nordic countries in the analysis and in the Netherlands, while the second combination is found in Belgium and France. A comparison of the solution term for the UK (natsta ${ }^{*}$ KNWGSOC) with all the solutions for the presence of 'post-national citizenship' suggests that our thesis of conjunctural 
causation might be valid. The presence of a 'knowledge society' combined with national stability leads to the presence of post-national citizenship (e.g. in Finland), while in combination with national instability (the UK), the presence of a 'knowledge society' prevents this outcome. However, taking into account our warnings about the limited empirical diversity and the possible additive influence of individual conditions, we should be cautious when seeking to draw general conclusions.

At any rate, we are inclined to conclude that there are some specific conditions which are only present in the UK and therefore cannot be included into the QCA model. A plausible interpretation of this is that the process of emerging post-national citizenship in the United Kingdom initially started but later slowed down (or even stopped) due to some specific factors. It is possible to detect a reaffirmation of national citizenship both symbolically and in terms of everyday political practice [cf. van Houdt, Suvarierol and Schinkel 2011]. ${ }^{10}$ This process is likely related to the historical changes resulting from the decline of the British Empire, which leads to a need for the country 'to redefine itself as a nation state and seek to create a national citizenship' [Stewart 1995: 67]. In this context, a citizenship policy specifically related to immigration was created [cf. Stewart 1995; Brubaker 1992]. Alongside this ongoing historical process, there are also significant current processes such as the increase in Scottish nationalism, the immigration of foreign workers (mostly Catholic Poles), anti-Muslim sentiment connected with the UK's role in the 'War on Terror' and the 2005 terrorist attack in London. These conditions may be deemed so specific that it is not possible to include them in the analytical model as a variable for standardised comparison.

\section{Conclusion}

Let us now consider these results in terms of our research objectives. We set out from the idea that we can expect to find elements of post-national citizenship within the framework of the EU. The classification of countries at a descriptive level reveals elements of post-national citizenship to be more present in three Nordic countries (in Finland, Sweden, and Denmark) and in three Western European countries (in Belgium, the Netherlands, and France).

As regards our goal of identifying the combinations of conditions that lead to the presence of more elements of post-national citizenship, we found that all four conditions from the analytical model appear in the simplified results: a postindustrial social structure, secularity, a knowledge-based society, and a stable national status. Among the $21 \mathrm{EU}$ countries in the analysis, the following two (sufficient) combinations of these four conditions led to 'post-national citizen-

10 The most recent proposal for a referendum on the United Kingdom's continued membership of the European Union could also be considered to be an indicator of this process. 
ship': (a) in secularised and post-industrial societies in which knowledge is less important; or (b) in societies with a stable national status where knowledge is important. However, we should be cautious about drawing general conclusions, especially about conjunctural causations, owing to the limitations mentioned above: (a) missing countries; (b) limited empirical diversity; and (c) existing combinations of conditions (with the singular exception of the UK) suggest that the effect of the observed conditions (factors) is more likely additive.

At the same time, the case of the United Kingdom proves that the process of moving towards post-national citizenship should not be understood as a stable and continuous process. It may be disrupted or delayed by several possible country-specific or global factors. In general, the proportion of citizens with the attributes of 'post-national' citizenship (active citizens, protest potential, etc.) is not very high, even in the group of 'post-national' citizenship countries. At first glance, this seems to contradict post-modernisation and globalisation trends. How can we explain the empirically weak presence of elements of 'post-national' citizenship in many EU countries? The first explanation concerns the micro level of citizens themselves. Being a 'post-national citizen' (e.g. active, cosmopolitan) requires special skills-both cognitive skills (knowledge, education) and the ability to exercise these capabilities (the problem of empowerment).

Another explanation relates to the macro level and the role of nation states. The analyses indeed show the presence of globalisation trends, but this does not mean that one can easily ignore the operation of 'classic' structural factors at the national level [cf. Marsh 2011; Li and Marsh 2008]. National political actors can be considered to be mediators between citizens and global (supranational) political and economic processes [cf. Marsh 2011: 78]. Even though it is a political fact that nation states are losing some of their sovereignty as a result of the processes of globalisation, studies do not confirm the thesis that the process of political globalisation is leading to the formation of global citizenship at the same degree of intensity as economic globalisation. We would argue that in some cases, for example, with respect to economic migration, the effects of globalisation have the opposite consequences. They serve to tighten the conditions for obtaining national citizenship, which consequently reinforces the symbolic and the real dimension of national citizenship [cf. van Houdt, Suvarierol and Schinkel 2011]. The latter situation, despite attempts to create a supranational European identity, can also be observed in the EU.

In the context of the global economic crisis, despite economic globalisation and the weaker sovereignty of nation states, we can expect that trends towards 'post-national' citizenship will temporarily decelerate or may even be suspended. According to van Houdt et al., the citizenship policies of developed European countries fit the concept of neo-liberal communitarian citizenship, which connects two seemingly opposite dimensions: (a) the 'neo-liberalisation' of citizenship, which involves an increased emphasis on the need to earn one's citizenship [ibid: 419-420]; (b) communitarianism, representing the increased 'sacralisation' 
of the nation in response to immigration [ibid.: 416-417]. It therefore appears that combining the classic concepts of citizenship, liberal and republican, does not necessarily lead to a 'post-national' concept of citizenship, but only to a transformation of the classic concept of citizenship based on the nation state. And this is true despite declarative (and normative) commitments to the creation of a supranational political community like the European Union.

MitJA HAFNER-FinK is an assistant professor of social science methodology at the Faculty of Social Sciences of the University of Ljubljana. He was president of the Slovenian Sociological Association (1998-2001). His research focuses on (political) participation, citizenship, (national) identity, and social science methodology. His recent publications include 'Bipolarity and/or Duality of Social Survey Measurement Scales and the Question-Order Effect' (with S. Uhan, Quality and Quantity, 2013), 'Political Participation, Democratisation and Citizens' Values in Europe' (Teorija in Praksa, 2012), and 'The Determinants of the Success of Transitions to Democracy' (with D. Fink-Hafner, Europe-Asia Studies, 2009).

BRINA MALNAR is an assistant professor of social science research methods at the Faculty of Social Sciences of the University of Ljubljana. In 1990 she joined the Public Opinion and Mass Communication Research Centre which houses the Slovenian Public Opinion survey. She has been involved with the European Social Survey since 2002. Her recent publications focus on research ethics, environment and health inequalities and include 'Trends in Subjective Health Assessment between 1981 and 2011 as an Indicator of Persistent Social Inequalities'(with S. Kurdija, Slovenian Journal of Public Health, 2012), 'Forty Years of Environmental Risk Perceptions: Evidence from the Slovenian Public Opinion Survey' (with Milan Šinko, Teorija praksa, 2012) and 'Trends in Inequalities between Statistics and Public Opinion' (Teorija in Praksa, 2011).

SAMO UHAN is an assistant professor of social science research methods at the Faculty of Social Sciences of the University of Ljubljana. His research focuses on cross-national research, religious changes in transition countries, EU integration process, and social science methodology. He was president of the Slovenian Sociological Association (2007-2010). His recent publications include 'Bipolarity and/or Duality of Social Survey Measurement Scales and the Question-Order Effect' (with M. Hafner-Fink, Quality and Quantity, 2013), 'Atheism in Post-socialist Conditions: the Case of Slovenia' (with M. Smrke, Teorija in Praksa, 2012), and 'Public Conceptions and Images of the European Union: The Case of Slovenia' (with F. Adam and M. Hafner-Fink, Innovation Wien, 2002). 


\section{References}

Achterberg, Peter. 2006. 'Class Voting in the New Political Culture. Economic, Cultural and Environmental Voting in 20 Western Countries.' International Sociology 21 (2): 237-261.

Bang, Henrik P. 2004. Everyday Makers and Expert Citizens: Building Political Not Social Capital. Retrieved 30 July 2011 (http://hdl.handle.net/1885/42117).

Bang, Henrik P. and Eva Soerensen. 2001. 'The Everyday Maker: Building Political Rather Than Social Capital.' Pp. 148-161 in Social Capital and Participation in Everyday Life, edited by Paul Dekker and E. M. Uslaner. London and New York: Routledge.

Barnes, Samuel H. 2006. 'The Changing Political Participation of Postcommunist Citizens.' International Journal of Sociology 36 (2): 76-98.

Beck, Ulrich. 2002. 'The Cosmopolitan Society and Its Enemies.' Theory, Culture E Society 19 (1-2): 17-44.

Beck, Ulrich and Elisabeth Beck-Grensheim. 2002. Individualization. London, Thousand Oaks, CA, and New Delhi: SAGE.

Benhabib, Seyla. 2002. 'Citizens, Residents, and Aliens in a Changing World: Political Membership in the Global Era.' Pp. 85-119 in The Postnational Self: Belonging and Identity, edited by U. Hedetoft and M. Hjort. Minneapolis, MN: University of Minnesota Press.

Benhabib, Seyla. 2005a. 'Disaggregation of Citizenship Rights.' Parallax 11 (1): 10-18.

Benhabib, Seyla. 2005b. 'Borders, Boundaries, and Citizenship.' PS: Political Science $\mathcal{E}$ Politics 38 (4): 673-677.

Benhabib, Seyla. 2007. 'Twilight of Sovereignty or the Emergence of Cosmopolitan Norms? Rethinking Citizenship in Volatile Times.' Citizenship Studies 11 (1): 19-36.

Berdahl, Robert M. 2005. 'German Reunification in Historical Perspective.' Berkeley Journal of International Law 23 (2): 496-505.

Berg-Schlosser, Dirk, Gisèle De Meur, Benoît Rihoux and Charles C. Ragin. 2009. 'Qualitative Comparative Analysis (QCA) as an Approach.' Pp. 1-32 in Configurational Comparative Methods. Qualitative Comparative Analysis (QCA) and Related Techniques, edited by B. Rihoux and C. C. Ragin. Los Angeles, CA, London, New Delhi and Singapore: SAGE.

Brubaker, Rogers. 1992. Citizenship and Nationhood in France and Germany. Cambridge, MA, and London: Harvard University Press.

Castles, Stephen. 2005. 'Hierarchical Citizenship in a World of Unequal Nation States.' PS: Political Science \& Politics 38 (4): 689-692.

Cohen, L. Jean. 1999. 'Changing Paradigms of Citizenship and the Exclusiveness of the Demos.' International Sociology 14 (3): 245-268.

Cronqvist, Lasse. 2007. Tosmana-Tool for Small-N Analysis [Version 1.3]. Marburg. Retrieved 24 November 2008 (http://www.tosmana.net).

Dalton, Russell J. 1996. Democracy and Its Citizens: Patterns of Political Change. Irvine, CA: Centre for the Study of Democracy at the University of California. Retrieved 20 January 2012 (http://escholarship.org/uc/item/9pn25985).

Dalton, Russell J. 2008. 'Citizenship Norms and the Expansion of Political Participation.' Political Studies 56 (1): 76-98.

Delanty, Gerard. 2000. Citizenship in a Global Age: Society, Culture, Politics. Buckingham and Philadelphia, PA: Open University Press. 
ESS. 2008. 'ESS Round 4: European Social Survey Round 4 Data (2008). Data file edition 4.0.' Bergen: Norwegian Social Science Data Services-Data Archive and Distributor of ESS data. Retrieved 5 May 2011 (http://ess.nsd.uib.no/ess/round4/).

ESS. 2011. 'ESS-4 2008 Documentation Report. Edition 4.0 (Appendix 3: Variables and questions).' Bergen: European Social Survey Data Archive, Norwegian Social Science Data Services. Retrieved 5 May 2011 (http://ess.nsd.uib.no/ess/round4/).

Eurostat. 2008. European Commission. Retrieved 29 April 2011 (http://epp.eurostat.ec.europa.eu/portal/page/portal/statistics/search_database).

EVS. 2010. 'European Values Study 2008, 4th Wave, Integrated Dataset. ZA4800 Data File Version 2.0.0 (2010-11-30).' Cologne: GESIS Data Archive. Retrieved 22 January 2010 (http://dx.doi.org/10.4232/1.10188).

EVS-GESIS. 2010. 'EVS 2008 Method Report.' GESIS-Technical Reports 2010/17. Retrieved 22 January 2011 (http://www.europeanvaluesstudy.eu/).

Faist, Thomas. 2009. 'The Transnational Social Question-Social Rights and Citizenship in a Global Context.' International Sociology 24 (1): 7-35.

Falk, Richard. 1994. 'The Making of Global Citizenship.' Pp. 127-140 in The Condition of Citizenship, edited by B. van Steenbergen. London, Thousand Oaks, CA, and New Delhi: SAGE.

Frey, Bruno S. 2003. 'Flexible Citizenship for a Global Society.' Politics, Philosophy $\mathcal{E}$ Economics 2 (1): 93-114.

Furia, Peter A. 2005. 'Global Citizenship, Anyone? Cosmopolitanism, Privilege and Public Opinion.' Global Society 19 (4): 331-359.

Held, David. 2004. Global Covenant. The Social Democratic Alternative to the Washington Consensus. Cambridge and Malden, MA: Polity Press.

Inglehart, Ronald. 1990. Cultural Shift in Advanced Industrial Societies. Princeton, NJ, and Oxford: Princeton University Press.

Inglehart, Ronald and Christian Welzel. 2005. Modernisation, Cultural Change, and Democracy. The Human Development Sequence. Cambridge and New York: Cambridge University Press.

Kaldor, Mary. 2003. Global Civil Society. An Answer to War. Cambridge, Oxford and Malden, MA: Polity Press and Blackwell Publishing.

Li, Yaojun and David Marsh. 2008. 'New Forms of Political Participation: Searching for Expert Citizens and Everyday Makers.' British Journal of Political Science 38 (2): 247-272.

Lipset, Seymour Martin. 1959. 'Some Social Requisites of Democracy: Economic Development and Legitimacy.' The American Political Science Review 53 (1): 69-105.

Marsh, David. 2011. 'Late Modernity and the Changing Nature of Policy: Two Cheers for Henrik Bang.' Critical Policy Studies 5 (1): 73-89.

Nash, Kate. 2009. 'Between Citizenship and Human Rights.' Sociology 43 (6): 1067-1083.

Painter, Joe. 2002. 'Multi-level Citizenship, Identity and Regions in Contemporary Europe.' Pp. 93-110 in Transnational Democracy. Political Spaces and Border Crossings, edited by J. Anderson. London: Routledge.

Putnam, Robert D. 1995. 'Tuning In, Tuning Out: The Strange Disappearance of Social Capital in America.' PS: Political Science \& Politics 28 (4): 664-683.

Ragin, Charles C. 2009. 'Qualitative Comparative Analysis Using Fuzzy Sets (fsQCA).' Pp. 87-121 in Configurational Comparative Methods. Qualitative Comparative Analysis (QCA) and Related Techniques, edited by B. Rihoux and C. C. Ragin. Los Angeles, CA, London, New Delhi and Singapore: SAGE. 
Ragin, Charles C., Kriss A. Drass and Sean Davey. 2006. 'Fuzzy-Set/Qualitative Comparative Analysis 2.0.' Tucson, AZ: Department of Sociology of the University of Arizona.

Rihoux, Benoît and Charles C. Ragin (eds.). 2009. Configurational Comparative Methods. Qualitative Comparative Analysis (QCA) and Related Techniques. Los Angeles, CA, London, New Delhi and Singapore: SAGE.

Rihoux, Benoît and Gisèle De Meur. 2009. 'Crisp-Set Qualitative Comparative Analysis (csQCA).' Pp. 33-68 in Configurational Comparative Methods. Qualitative Comparative Analysis (QCA) and Related Techniques, edited by B. Rihoux and C. C. Ragin. Los Angeles, CA, London, New Delhi and Singapore: SAGE.

Rose, David and Eric Harrison. 2007. 'The European Socio-economic Classification: A New Social Class Schema for Comparative European Research.' European Societies 9 (3): 459-490.

Schneider, Carsten Q. 2009. The Consolidation of Democracy. Comparing Europe and Latin America. Abingdon and New York: Routledge.

Schneider, Carsten Q. and Claudius Wagemann. 2010. 'Standards of Good Practice in Qualitative Comparative Analysis (QCA) and Fuzzy-Sets.' Comparative Sociology 9 (3): 397-418.

Schneider, Carsten Q. and Claudius Wagemann. 2012. Set-Theoretic Methods for the Social Sciences. A Guide to Qualitative Comparative Analysis. Cambridge, New York, Melbourne, Madrid, Cape Town, Singapore, Sao Paolo, Delhi, Mexico City: Cambridge University Press.

Schwartz, Shalom H. 2007. 'Value Orientations: Measurement, Antecedents and Consequences across Nations.' Pp. 169-203 in Measuring Attitudes Cross-Nationally. Lessons from the European Social Survey, edited by R. Jowell, C. Roberts, R. Fitzgerald and E. Gillian. London, Thousand Oaks, CA, New Delhi and Singapore: SAGE.

Shore, Cris. 2004. 'Whither European Citizenship? Eros and Civilization Revisited.' European Journal of Social Theory 7 (1): 27-44.

Silver, Hilary. 2010. 'The Social Integration of Germany since Unification.' German Politics and Society 28 (1): 165-188.

Soysal, Yasemin Nuhoğlu. 1994. Limits of Citizenship: Migrants and Postnational Membership in Europe. Chicago, IL, and London: The University of Chicago Press.

Soysal, Yasemin Nuhoğlu. 1996. 'Changing Citizenship in Europe. Remarks on Post-national Membership and the National State.' Pp. 17-29 in Citizenship, Nationality and Migration in Europe, edited by D. Cesarani and M. Fulbrook. London and New York: Routledge.

Soysal, Yasemin Nuhoğlu. 2002. 'Citizenship and Identity: Living in Diasporas in Post-war Europe?' Pp. 137-151 in The Postnational Self: Belonging and Identity, edited by U. Hedetoft and M. Hjort. Minneapolis, MN: University of Minnesota Press.

Stewart, Angus. 1995. 'Two Conceptions of Citizenship.' The British Journal of Sociology 46 (1): $63-78$.

Turner, Bryan S. 2000. 'Liberal Citizenship and Cosmopolitan Virtue.' Pp. 18-32 in Citizenship and Democracy in a Global Era, edited by A. Vandenberg. New York: St. Martin's Press.

Turner, Bryan S. 2001. 'The Erosion of Citizenship.' British Journal of Sociology 52 (2): 189-209.

UNDP. 2012. International Human Development Indicators. New York: UNDP. Retrieved 9 March 2012 (http://hdrstats.undp.org/en/indicators/103106.html).

van Houdt, Friso, Semin Suvarierol and Willem Schinkel. 2011. 'Neoliberal Communitarian Citizenship: Current Trends Towards "Earned Citizenship" in the United Kingdom, France and the Netherlands.' International Sociology 26 (3): 408-432. 
Yamasaki, Sakura and Benoît Rihoux. 2009. 'A Commented Review of Applications.' Pp. 123-145 in Configurational Comparative Methods. Qualitative Comparative Analysis (QCA) and Related Techniques, edited by B. Rihoux and C. C. Ragin. Los Angeles, CA, London, New Delhi and Singapore: SAGE. 


\section{Appendices}

Appendix 1. Classification of European countries on the basis of the three indicators for post-industrial society

Dendrogam using Ward linkage (based on Z-scores)

Rescaled Distance Cluster Combine

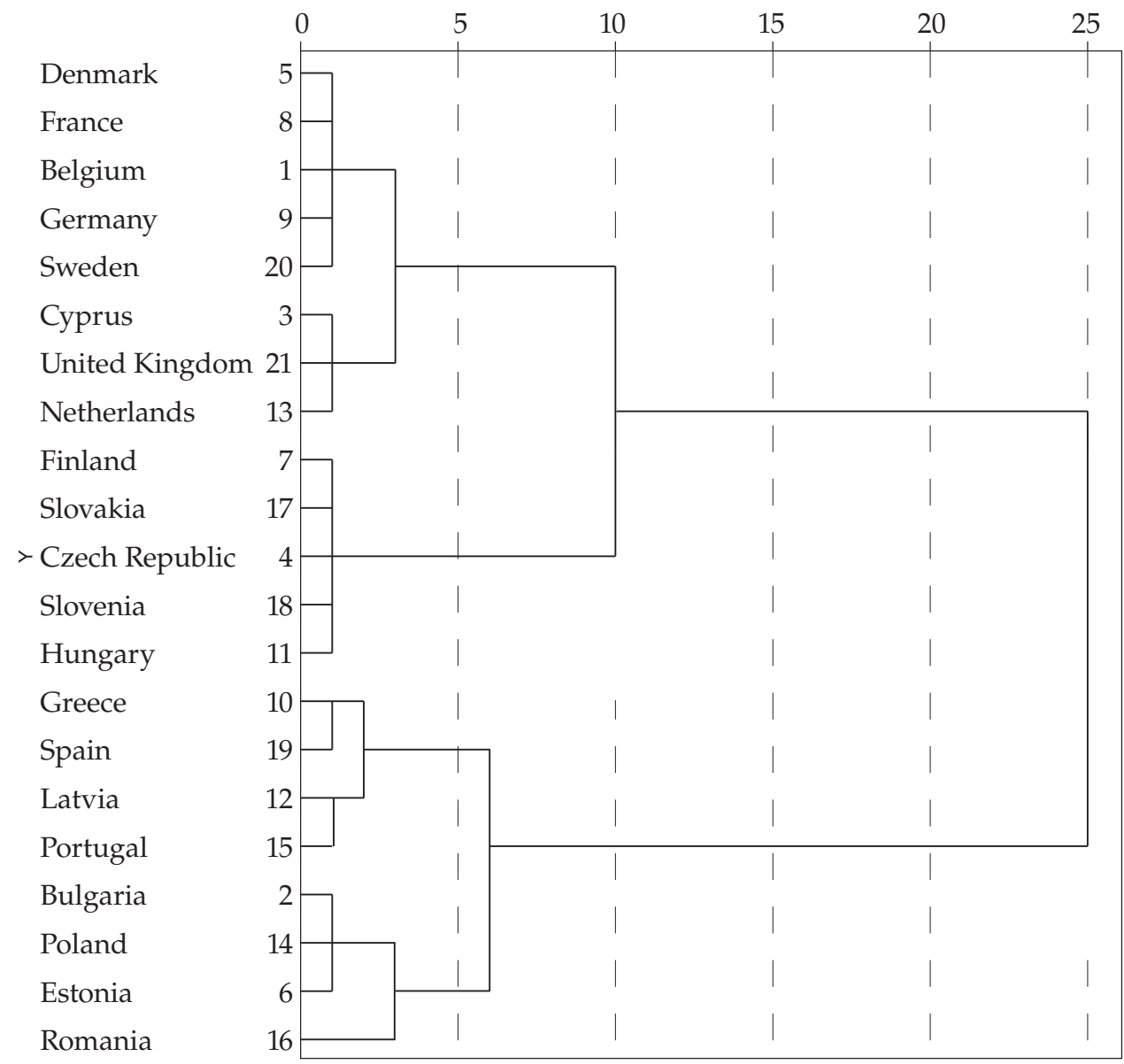

Source: ESS 2008, Eurostat 2008. 


\begin{tabular}{llccc}
\hline Structure of clusters: & & $\begin{array}{c}\text { Middle } \\
\text { class } \\
(\% ; \text { ESeC } \\
2-4,6) \\
(\text { ESS 2008) }\end{array}$ & $\begin{array}{c}\text { Income gap } \\
- \text { quintile } \\
\text { ratio } \\
\text { (Eurostat } \\
2008)\end{array}$ & $\begin{array}{c}\text { Employed } \\
\text { in service } \\
\text { sector }(\%) \\
(\text { Eurostat } \\
2008)\end{array}$ \\
\hline 1. & Mean & 48.2 & 4.19 & 72.0 \\
Post-industrial & Minimum & 44.1 & 3.5 & 63.9 \\
middle-class societies $(N=8)$ & Maximum & 54.7 & 5.5 & 81.1 \\
2. & Mean & 31.0 & 5.98 & 61.0 \\
High-inequality & Minimum & 19.8 & 5.4 & 43.1 \\
industrial societies $(N=8)$ & Maximum & 38.4 & 7.1 & 73.8 \\
3. & Mean & 38.3 & 3.66 & 57.5 \\
Low-inequality & Minimum & 30.7 & 3.3 & 52.7 \\
industrial societies $(N=5)$ & Maximum & 44.0 & 4.1 & 63.0 \\
\hline
\end{tabular}




\section{Appendix 2. Classification of European countries on the basis of the three indicators for secularisation}

Dendrogam using Ward linkage (based on Z-scores)

Rescaled Distance Cluster Combine

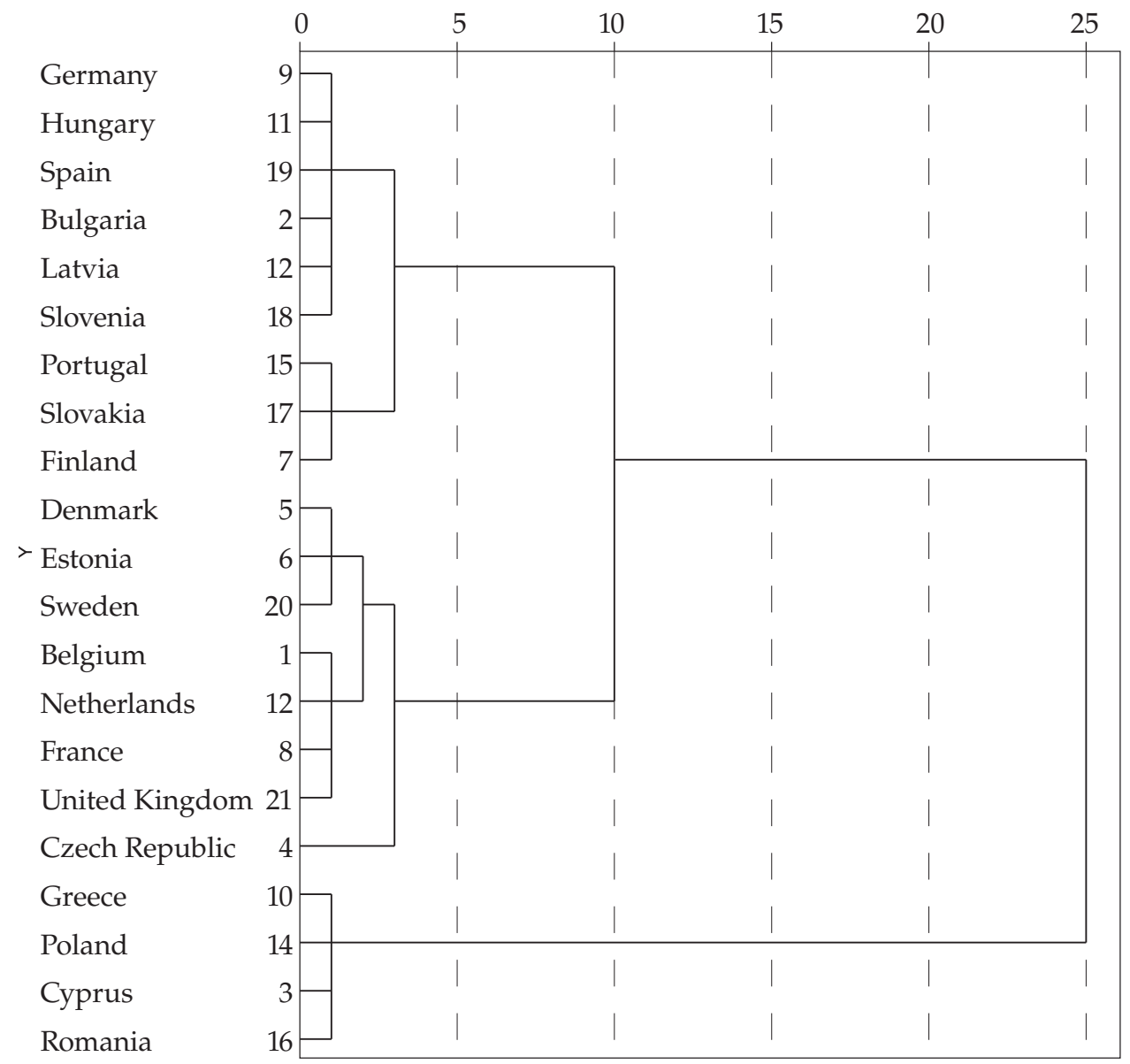

Source: ESS 2008. 


\begin{tabular}{llccc}
\hline Structure of clusters: & $\begin{array}{c}\text { Doesn't } \\
\text { attend } \\
\text { religious } \\
\text { services at } \\
\text { all }(\%)\end{array}$ & $\begin{array}{c}\text { Doesn't } \\
\text { pray outside } \\
\text { religious } \\
\text { services } \\
(\%)\end{array}$ & $\begin{array}{c}\text { Religiosity } \\
- \text { self-per- } \\
\text { ception } \\
(\text { mean, } \\
0-10)\end{array}$ \\
\hline 1. & 47.4 & 55.0 & 3.87 \\
Highly secularised societies & Minimum & 33.1 & 47.7 & 2.29 \\
$(N=8)$ & Maximum & 63.3 & 71.6 & 4.92 \\
2. & Mean & 28.9 & 31.6 & 4.82 \\
Secularised societies & Minimum & 20.3 & 17.9 & 4.07 \\
$(\mathrm{~N}=9)$ & Maximum & 43.4 & 41.5 & 5.99 \\
3. & Mean & 4.2 & 4.9 & 6.53 \\
Less secularised societies & Minimum & 2.3 & 2.7 & 6.31 \\
$(\mathrm{~N}=4)$ & Maximum & 5.3 & 7.0 & 6.76 \\
\hline
\end{tabular}




\section{Appendix 3. Classification of European countries on the basis of the three indicators for knowledge-based societies}

Dendrogam using Ward linkage (based on Z-scores)

Rescaled Distance Cluster Combine

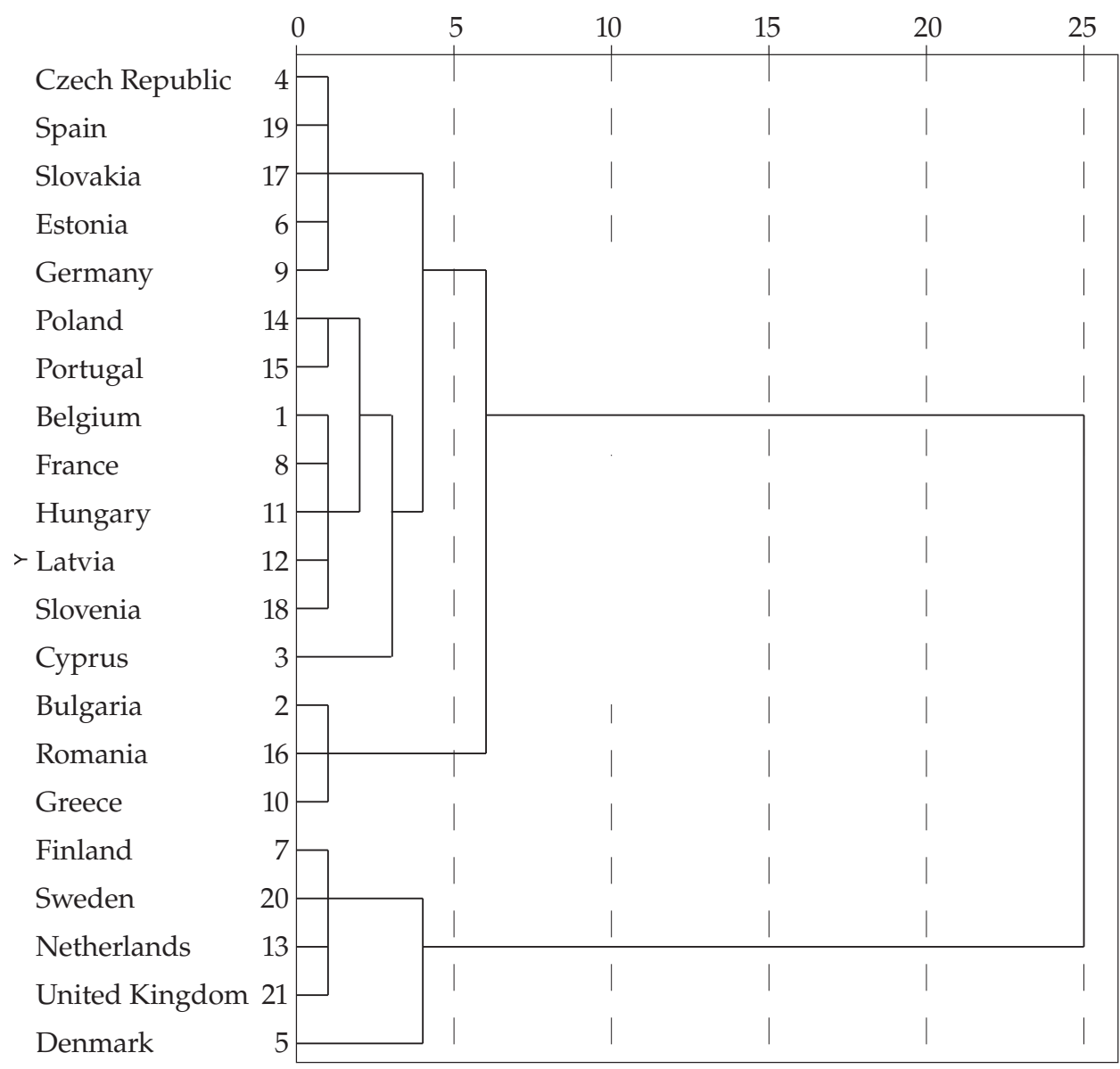

Source: Eurostat 2008, HDR 2008. 


\begin{tabular}{llccc}
\hline Structure of clusters: & & $\begin{array}{c}\text { Internet users } \\
\text { \%, HDR } \\
\text { 2008) }\end{array}$ & $\begin{array}{c}\text { Public ex- } \\
\text { education } \\
\text { (\% of GDP; } \\
\text { Eurostat 2008) }\end{array}$ & $\begin{array}{c}\text { Life-long } \\
\text { learning } \\
\text { \%; Eurostat } \\
2008)\end{array}$ \\
\hline 1. & Mean & 83.3 & 6.36 & 22.44 \\
Highly knowledge-based & Minimum & 76.0 & 5.4 & 17.0 \\
societies $(N=5)$ & Maximum & 87.7 & 8.0 & 30.0 \\
2. & Mean & 54.250 & 4.96 & 6.25 \\
Low or average knowledge- & Minimum & 28.8 & 3.7 & 1.4 \\
based societies $(N=16)$ & Maximum & 75.5 & 7.1 & 13.9 \\
\hline
\end{tabular}

